\title{
THERMODYNAMIC AND KINETIC STUDIES FOR THE BINDING OF LEAD ION BY CHELATING WITH THEOPHYLLINE 1,3-DIMETHYLXANTHINE (THERAPY DRUG)
}

\author{
HUDA N AL-ANI* \\ Department of Chemistry, College of Science, University of Baghdad, Jadiriya, Baghdad, Iraq. Email: hudanajim2005@yahoo.com
}

Received: 13 May 2019, Revised and Accepted: 19 June 2019

ABSTRACT

Objective: Chelating therapy is a medical procedure that involves the administration of chelating agents to remove heavy metals from the body; chelating agents detoxify heavy metals and toxins, converting them to inactive forms which were excreted out from the body. This work demonstrates the complication of the drug with toxic heavy metal lead (П) ion.

Methods: All the experiments were performed at different temperature $(303,308,313,318$, and 323$){ }^{\circ} \mathrm{K}$, by spectrophotometric method. The electronic spectra of the mixture of drug and lead ion show a bathochromic (red) shift in $\Lambda_{\text {max }}$, the absorbance change caused by a complex arrangement between the lead ion and drug.

Results: The stoichiometry of the complex formed was calculated using continuous variation method, it was found (1:2) that the durability constant was estimated that the standard thermodynamic parameters $\Delta \mathrm{H}^{\circ}, \Delta \mathrm{G}^{\circ}$, and $\Delta \mathrm{S}^{\circ}$ were determined, the negative values of free energy changes $\Delta \mathrm{G}^{\circ}$ indicate a spontaneous complexation process. The positive values of enthalpy change indicate an endothermic process with an increase in entropy change $\Delta S^{\circ}$ (positive), that means the process in an entropy driven.

Conclusion: The kinetic studies of the complexation of drug and ion were found to follow the second-order reaction, which was confined by the straight line and a high rate constant.

Keywords: Chelating therapy, Complexation, Stoichiometry, Kinetic, Drug.

(c) 2019 The Authors. Published by Innovare Academic Sciences Pvt Ltd. This is an open access article under the CC BY license (http://creativecommons. org/licenses/by/4. 0/) DOI: http://dx.doi.org/10.22159/ajpcr.2019.v12i8.34085

\section{INTRODUCTION}

Drugs with variant active groups existing in its structure, which be able to connect with lead ions existing in the human body [1]. Metal-drug complexes are found in more operative than parent drugs [2]. Many researchers engage in drugs chemistry due to its usage in the study of medicinal. The fixity of complexes with metal and medicinal drugs act a major role in the chemical and biological activity $[3,4]$. The "chelation therapy" term generally impute to the use of pro ligands such as drugs to deal with disorders resulting from the presence of not desirable lead ions increasing from disease or intoxication. Chelation therapy is the preferred medical treatment for lowering the toxic of metals effects like $(\mathrm{Pb})$ ion. Chelating agents are able to bind with toxic metal ions to create complex structures that are handily secreted from the body, eliminating them from extracellular or intracellular spaces [5]. Metals are an complete part of a lot of structural and functional compounds in the body, the important role of metals in pathological and physiological processes has constantly been of benefit to researchers. In overall, the object of chelation is to remove toxic ions of metals from the sites which vulnerable in critical organs [6]. This needs that chemical familiarity of complex agent for lead ions is superior to affinity of metal ions for sentimental biological molecules [7]. Chelating agents are with huge importance in treating of intoxications and overload with metals. Metal complexes are considerably used in several fields, such as pharmaceuticals, biological processes, separation mechanics, and analytical practicability [8]. Most of d-block elements format complex. There are various kinds of ligand used for complexation. For this investigation, we chose a drug theophylline 1,3-dimethylxanthine (BDH) having molecular structure $\mathrm{C}_{7} \mathrm{H}_{8} \mathrm{O}_{2} \mathrm{~N}_{4} \cdot \mathrm{H}_{2} \mathrm{O}$. Theophylline, so well-known as 1,3-dimethylxanthine, is a methylxanthine drug adopted therapy for respiratory diseases like chronic obstructive pulmonary disease and asthma under a variety of brand names. As a member of the xanthine family, it bears structural and pharmacological similarity to caffeine and the obromine, and found in nature; it is present in cocoa (Theobroma cacao) and tea (Camellia sinensis). A little amount of theophylline is one of the products of caffeine metabolic treating in liver [9]. The basic operations of theophylline contain.

Resting the bronchial smooth muscle growing muscle of heart efficiency and contractility; such as a positive inotrope, raising heart rate: Positive chronotropic, raising blood pressure, raising renal blood flow, antiinflammatory effects, and central nervous system stimulatory effect chiefly on the center of medullar respiratory center.

Chelating capacitates metals to transfer from or to vulnerable target locations and to hinder or simplify their carcinogenic potential. In the opposite sense, metals are able of legend sweeping through complication or mixed complex formation-the latter existing the result of reaction with bilateral complexes [10]. Accordingly, metal complexes be able to employed for the transfer of chosen organic chemotherapeutic drugs to target organs, or for decor oration of those toxic organic compounds which are capable, before or after metabolic activating, or reply with (drug:metal) or (2:1) metal complexes (Fig. 1).

Lead $(\mathrm{Pb})$ is regarded such as one of the most risks and accumulative environmental pollutants that impact all biological system through disclosing from air, food sources, and water [11]. Lead exposure induced clinic pathological changes through toxicity occurred to kidney and endocrine system [12]. Lead is toxic heavy metals which are familiar to cause aboard range of biochemical, physiological, and behavior in humans. Due to its perverseness in lead poisoning still, stay an important health problem [13].

Lead is toxic to many organs of the body. It is especially dangerous because it can damage the brain and peripheral nerves. These nerves connect the brain and spinal cord to the rest of the body. Lead can 
affect anyone, but children are especially at risk because they are still growing rapidly. The toxic affecting of lead differ extremely testify as obscure changes in neuron cognitive function in low-level presentment or as potentially fatal encephalopathy of severe lead poisoning. The effective chelation using supplements that bind to toxins allows them to be effectively and safely transported from the body [14]. Aim of this research to study the influence of theophylline 1,3-dimethylxanthine (BDH) (therapy drugs) and lead by appliance of ultraviolet (UV)-visible spectroscopic method, the sequent calculation was done.

- The stoichiometric ratio of complexes

- The rate constant and the order of the reaction

- Thermodynamic parameters $\left(\mathrm{DH}^{\circ}, \mathrm{DG}^{\circ}\right.$, and $\left.\mathrm{DS}^{\circ}\right)$ and equilibrium constant for the reaction.

\section{EXPERIMENTAL}

\section{Reagent and chemicals}

Pure deionized water was provided from LV-08 ultrapure water apparatus. All absorption spectra were obtained with the UV-Vis Spectra photometer: UV-1800, by $1 \mathrm{~cm}$ path length a quartz cell. The absorbance of theophylline 1,3-dimethylxanthine and lead ion (П) was calculated in a wavelength (271-291 nm). Theophylline 1,3-dimethylxanthine and lead ion (П) were purchased from HIMEDIA and MERCK, respectively. Stock solution of theophylline $\left(10^{-3} \mathrm{M}\right)$ concentration was prepared by dissolving $(0.099 \mathrm{~g})$ in $50 \mathrm{ml}$ flask using distilled water as a solvent and $\left(10^{-3} \mathrm{M}\right)$ was prepared by dissolving $(0.033 \mathrm{~g})$ of lead nitrate in $100 \mathrm{ml}$ volumetric flask using distilled water as a solvent. Series of solution differ in a concentration ranging from $10^{-4}-2 \times 10^{-5} \mathrm{M}$ were prepared by dilution from their stock solutions of drug and the absorption spectrum was taken for them.

\section{Stoichiometric analysis}

The stoichiometry of (theophylline-metal) complexation was studied with (jobs method) the continuous variation method [15], with a series of many solutions have a mole fraction in between $(0.1-1)$ by mixing various volumes of the drug (theophylline) and lead ion (П) the stock solutions of a concentration $\left(10^{-4} \mathrm{M}\right)$ for each [16], these solutions were allowed to stand for the equilibrium time, and then we measured the absorbance with against reagent blank. The results obtained were plotted against $(\mathrm{X})$ mole fraction.

Estimation of molar absorptive of the complex by prepared serialize of the solution of 1:2 (lead:drug) complex in the range of $1 \times 10^{-5}-5 \times 10^{-5} \mathrm{M}$ concentration, then recording the absorbance spectrum of them. Then, we determine the rate constant and the order of interaction of lead and drug, and the absorbance was recorded with time at different temperatures $303,308,313,318$, and $323{ }^{\circ} \mathrm{K}$ in $0-120 \mathrm{~min}$. We determined the equilibrium constant by recording the absorption spectrum of them at different temperatures $303,308,313,318$, and $323^{\circ} \mathrm{K}$.

\section{RESULTS AND DISCUSSION}

\section{Absorption spectroscopy}

The UV-Vis absorption investigation was taken to each drug and lead ion and drug-lead ion complex. The UV-Vis absorbance disclosure a shift in $K_{\text {I }}$ l (271-291 nm) (Table 1) shows the calculated data for absorbance of (drug - lead [ח]) complex with different concentration, the electronic spectra of the mixture of drug-Pb complex show a bath chromic shift

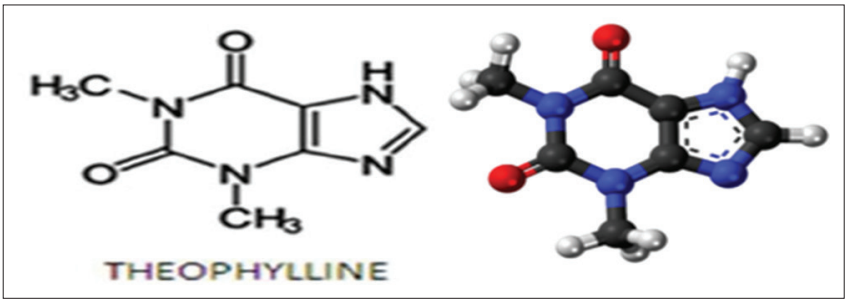

Fig. 1: Structural formula of theophylline 1,3-dimethyl- xanthine (BDH) (therapy drugs) (redshift) to the longer wavelength at $\Lambda_{m a x} l(291 \mathrm{~nm})$ which attributed to $\left(\mathrm{n} \rightarrow \pi^{*}\right)$ transition to the extent $(\Delta \lambda=20 \mathrm{~nm})$, and the change in the absorbance due to complex formation between metal and drug $[17,18]$. Fig. 2 shows the calibration curve between absorbance and different concentration of drug- $\mathrm{Pb}$ complex.

\section{Stoichiometric ratio of (drug-Pb) complex analysis}

By use the continuous variation methods to estimate stoichiometry of (drug-lead [П]) complex [19]. The coordination number (n) could be computed from the plot of absorbance of (drug-lead (П)) complex at $K_{\max } \mathrm{l}(291 \mathrm{~nm})$ against mole fraction shows in Table 2, so it clear from Fig. 3 the jobs method plot, prove that Stoichiometric ratio of (drug- lead [ח]) complex at $298^{\circ} \mathrm{K}$ is $2: 1$.

\section{Determination of the equilibrium constant Keq}

The equilibrium constant Keq can be calculated using the continuous variation method [20].

$\mathrm{M}+$ Drug $\stackrel{\leftarrow}{\rightarrow}[\mathrm{M}$ - Drug] complex

The interaction is able to characterized by equilibrium: (1) Where Keq to describe the stoichiometric stability constant, to describe $(\mathrm{Pb})$ metal ion (M), and to present the chelator (drug), and square brackets denote concentrations of interacting types at equilibrium [21]

drug $-\mathrm{Pb}$ complex eq: The concentration of complex created between the lead-drug at the equilibrium.

$[\mathrm{Pb}]$ eq: The concentration of $\mathrm{Pb}$ ion at the equilibrium

[drug]eq: The concentration of drug at the equilibrium.

$[$ drug-Pb]eq $=$ absorbance $(\max ) / \varepsilon l$

$\varepsilon$ : The molar absorptive for (drug-Pb) complex $\left(\mathrm{cm}^{-1} \cdot \mathrm{mol}^{-1} \cdot \mathrm{L}\right)$.

l: The path length in $(\mathrm{cm})$.

Absorbance $(\max )=$ The maximum absorbance to (drug- $\mathrm{Pb})$ complex.

The molar absorptive $\varepsilon$ of (drug-Pb) complex was computed with recordation the absorbance of collection concentration of (2:1) complex

Table 1: The calculated data for absorbance of (drug - Pb (ח)) complex with different concentration

\begin{tabular}{lll}
\hline $\mathbf{C} \times \mathbf{1 0}^{-\mathbf{5}}$ (drug) (M) & Abs. (nm) & $\boldsymbol{K}_{\max }(\mathbf{n m})$ \\
\hline 0 & 0 & 291 \\
3 & 0.059 & 292 \\
4 & 0.079 & 291 \\
6 & 0.120 & 291 \\
7 & 0.140 & 291 \\
9 & 0.180 & 291 \\
10 & 0.197 & 291 \\
\hline
\end{tabular}

Table 2: The mole fraction, the absorbance of a mixture of (drug - Pb) complex at $298 \mathrm{~K}$ and at $\hat{\kappa}_{\text {max }}(291 \mathrm{~nm})$

\begin{tabular}{lll}
\hline $\mathbf{X}_{\text {drug }}$ (the mole fraction) & Abs. & $\boldsymbol{\Lambda}_{\max }$ \\
\hline 0 & 0 & 292 \\
0.1 & 0.122 & 292 \\
0.2 & 0.511 & 291 \\
0.3 & 0.796 & 291 \\
0.4 & 0.699 & 291 \\
0.5 & 0.619 & 291 \\
0.6 & 0.511 & 291 \\
0.7 & 0.411 & 291 \\
0.8 & 0.315 & 291 \\
0.9 & 0.219 & 291 \\
1 & 0 & 291 \\
\hline
\end{tabular}


and plotting absorbance versus concentration at temperature 303, 308, 313,318 , and $323^{\circ} \mathrm{K}$, as illustrated in Figs. 4 and 5, Table 3 illustrated the calculated absorbance for concentration $\left(0.5 \times 10^{-5-} 4 \times 10^{-5}\right) \mathrm{M}$ of the $2: 1$ (drug-Pb) complex at temperature $303,308,313,318$, and $323{ }^{\circ} \mathrm{K}$, which given a straight line with a slope equals to $\varepsilon$ e is molar absorptivity of the complex (L. mol ${ }^{-1} \mathrm{~cm}^{-1}$ ) as illustrated in Table 4 [22,23].

Stability constant ( $\mathrm{k}$ eq): Using continuous variation method. The equilibrium constant be able to computed as demonstrate in

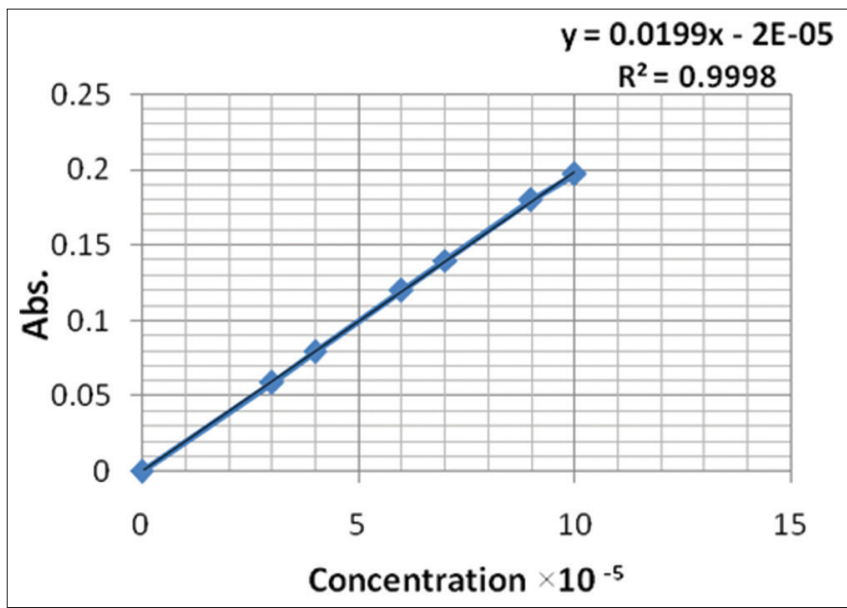

Fig. 2: The calibration curve between absorbance and different concentration of (drug-Pb) complex

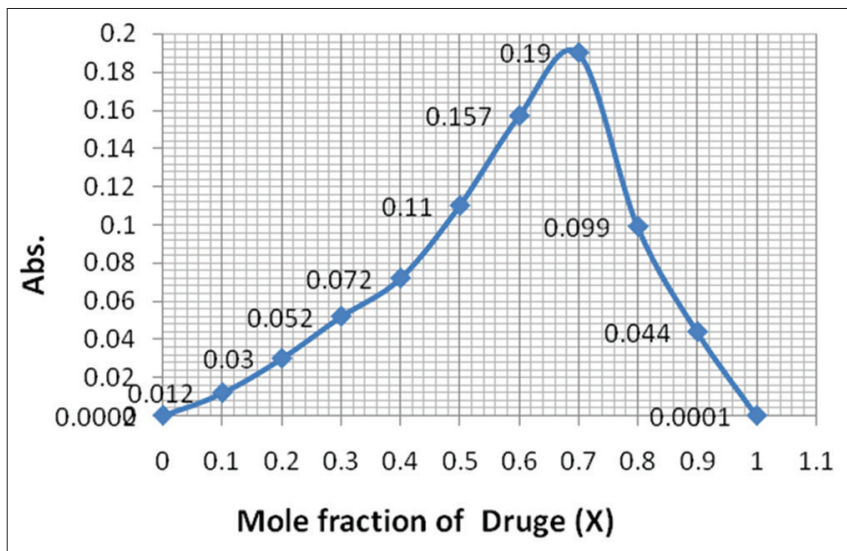

Fig. 3: The jobs method plot for the formation of (drug -Pb) complex $\Lambda_{\max } 1(291 \mathrm{~nm})$

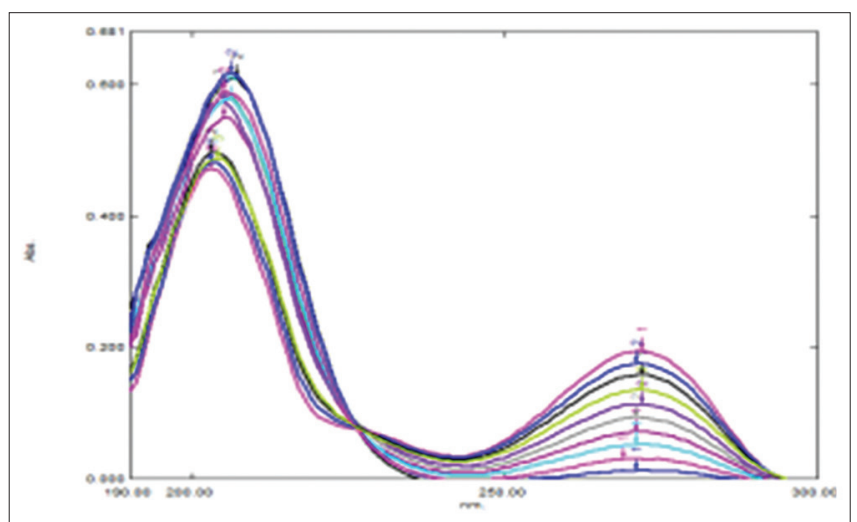

Fig. 4: The UV -VIS Absorption spectra with variant Concentration (0.5 $\times 10-5-4 \times 10-5) \mathrm{M}$ of the $(1: 2)$ (drug- $\mathrm{Pb}$ ) complex at variant temperature $(303,308,313,318,323){ }^{\circ} \mathrm{K}$
Equation (2) [24,25]:

$\varepsilon$ complex $=5500 \mathrm{~L} \cdot \mathrm{mol}^{-1} \mathrm{~cm}^{-1}$

$\mathrm{k}$ eq $=[\mathrm{Pb}-\text { druge complex }]_{\mathrm{eq}} /[\mathrm{Pb}]_{\mathrm{eq}}[\mathrm{drug}]_{\mathrm{eq}}$

Keq which is independent of the concentration but depends on the temperature.

The results clarified that stability constant keq changes somewhat with range of temperature adopted in this research $303,308,313,318$, and $323^{\circ} \mathrm{K}$, it increases with rise in temperature for drug-Pb complex that signifies stability of complex increase with temperature, which denotes the bond becomes stronger between them [26,27].

keq $=7.98743 \times 10^{4} \mathrm{~L} \cdot \mathrm{mol}^{-1}$

\section{Thermodynamic parameters}

The free energy changes $\Delta \mathrm{G}^{\circ}$, the enthalpy changes $\Delta \mathrm{H}^{\circ}$, and the entropy changes $\Delta \mathrm{S}^{\circ}$ were computed for complex clarified in Fig. 6 . The $\Delta \mathrm{H}^{\circ}$ was computed using substituting the valuate of slope of plot (ln Keq vs. 1/T) in vant Hoff Equation (1), the result clarified in Table 5 and $[28,29]$.

$$
\begin{aligned}
& \ln \mathrm{Keq}=-\Delta \mathrm{H}^{\mathrm{o}} / \mathrm{RT}^{+} \Delta \mathrm{S}^{\mathrm{o}} / \mathrm{R}^{ \pm} \\
& \text {Slope }=-\Delta \mathrm{H}^{\mathrm{o}} / \mathrm{R}
\end{aligned}
$$

$\mathrm{R}=$ The gas constant.

The $\left(\Delta G^{\circ}\right)$ change in Gibbs free energy be able to calculated from Equation (2), the relationship between $\Delta G^{\circ}$ and $K_{e q}$ and $\left(\Delta S^{\circ}\right)$ from Equation (3).

$$
\begin{aligned}
& \ddot{A} G^{o}=-R T \ln K e q \\
& \Delta G^{\circ}=\Delta H^{\circ}-T \Delta S^{o}
\end{aligned}
$$

\section{$\Delta \mathrm{H}^{\circ}=1305 \times 8.314=10849.77 \mathrm{~J} / \mathrm{mol}$}

The $\Delta \mathrm{G}^{\circ}$ is very important in deciding the direction of process and position of equilibrium. The negative values of Gibbs free energy for these interaction indicate the spontaneous process in the direction of equilibrium and increase with the increase in temperature as clarified in Table 5. The enthalpy of interaction has an appositive value indicating that the formation of drug- $\mathrm{Pb}$ complex is endothermic [30]. The positive value of enthalpy and entropy change also refers to the type of interaction between drug and $\mathrm{Pb}$ ion which is electrostatic in nature [31].

\section{Interaction kinetics}

To investigate the interaction kinetic of ( $\mathrm{Pb}[\Pi]$-drugs) complex, the absorbance of 1:2 complex was followed with time (Table 6). The first- and second-order rats equation were applied.

Table 3: The calculated absorbance for concentration $\left(0.5 \times 10^{-5}-4 \times 10^{-5}\right) \mathrm{M}$ of the (1:2) (drug-Pb) complex at temperature $303,308,313,318$, and $323^{\circ} \mathrm{K}$

\begin{tabular}{llllll}
\hline Concentration (M) & \multicolumn{6}{l}{ Absorbance } \\
\cline { 2 - 6 } & $\mathbf{3 0 3}^{\circ} \mathbf{K}$ & $\mathbf{3 0 8}^{\circ} \mathbf{K}$ & $\mathbf{3 1 3}^{\circ} \mathbf{K}$ & $\mathbf{3 1 8}^{\circ} \mathbf{K}$ & $\mathbf{3 2 3}^{\circ} \mathbf{K}$ \\
\hline $0.5 \times 10^{-5}$ & 0.055 & 0.057 & 0.059 & 0.066 & 0.068 \\
$1 \times 10^{-5}$ & 0.085 & 0.093 & 0.098 & 0.099 & 0.133 \\
$1.5 \times 10^{-5}$ & 0.159 & 0.177 & 0.184 & 0.189 & 0.192 \\
$2 \times 10^{-5}$ & 0.205 & 0.212 & 0.200 & 0.202 & 0.241 \\
$2.5 \times 10^{-5}$ & 0.277 & 0.280 & 0.281 & 0.283 & 0.292 \\
$3 \times 10^{-5}$ & 0.323 & 0.330 & 0.322 & 0.323 & 0.348 \\
$3.5 \times 10^{-5}$ & 0.377 & 0.382 & 0.382 & 0.367 & 0.397 \\
$4 \times 10^{-5}$ & 0.420 & 0.396 & 0.438 & 0.440 & 0.466 \\
\hline
\end{tabular}




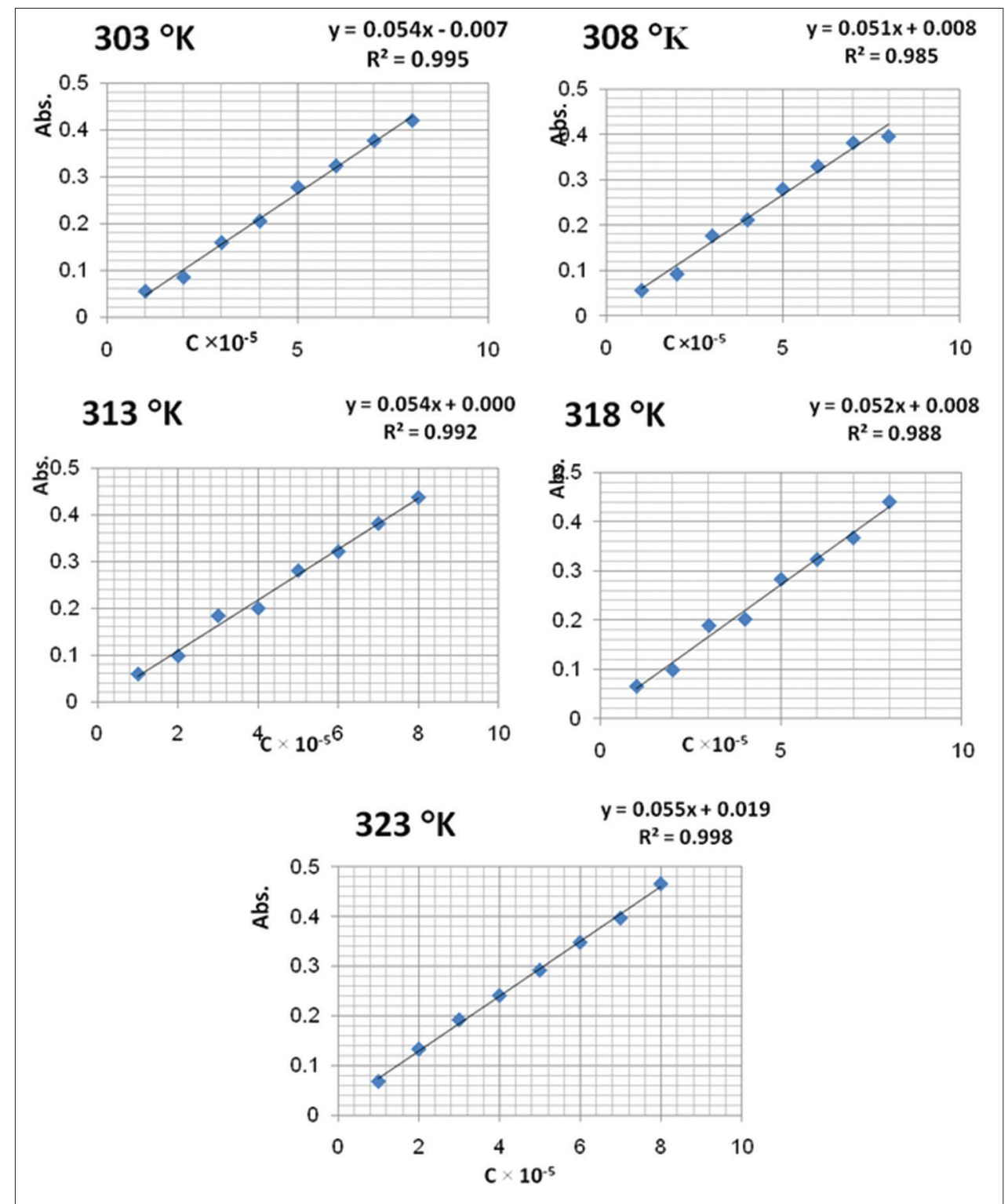

Fig. 5: The absorbance against concentration $\left(0.5 \times 10^{-5}-4 \times 10^{-5}\right) \mathrm{M}$ of the $1: 2$ (drug-Pb) complex at temperature $303,308,313,318$, and $323^{\circ} \mathrm{K}$

Table 4: The experimental thermodynamic parameters for drug-Pb complex at temperature $303,308,313,318$, and $323^{\circ} \mathrm{K}$

\begin{tabular}{llllll}
\hline Temperatures $\left({ }^{\circ} \mathbf{K}\right)$ & $\left.\mathbf{1} / \mathbf{T} \times \mathbf{1 0}^{-\mathbf{3}}{ }^{\circ} \mathbf{K}\right)^{-\mathbf{1}}$ & $\mathbf{E \times 1 \mathbf { 1 0 } ^ { \mathbf { 3 } }}$ & $\mathbf{k e q \times 1 \mathbf { 1 } ^ { \mathbf { 4 } }}$ & $\mathbf{R}^{\mathbf{2}}$ & $\mathbf{L n} \mathbf{~ k e q}$ \\
\hline 303 & 3.3000 & 5.4000 & 6.2999 & 0.9950 & 11.0509 \\
308 & 3.2460 & 5.1000 & 6.2822 & 0.9850 & 11.0481 \\
313 & 3.1950 & 5.4000 & 6.9013 & 0.9920 & 11.1420 \\
318 & 3.1450 & 5.2000 & 7.9444 & 0.9880 & 11.2828 \\
323 & 3.0960 & 5.5000 & 7.9874 & 0.9980 & 11.2882 \\
\hline
\end{tabular}

Table 5: The calculated thermodynamic parameters for ( $\mathrm{Pb}[\Pi]-d r u g)$ complex at temperature $303,308,313,318$, and $323^{\circ} \mathrm{K}$

\begin{tabular}{|c|c|c|c|}
\hline $\begin{array}{l}\text { Temperatures } \\
(\mathrm{K})\end{array}$ & $\Delta \mathbf{H}^{\circ}\left(\mathrm{J} \cdot \mathrm{mol}^{-1}\right)$ & $\Delta \mathrm{G}^{\circ}\left(\mathrm{J} \cdot \mathrm{mol}^{-1}\right)$ & $\Delta \mathrm{S}^{\circ}\left(\mathrm{J} \cdot \mathrm{mol}^{-1} \mathrm{~K}^{-1}\right)$ \\
\hline 303 & 10849.77 & -27838.73594 & 127.684838 \\
\hline 308 & 10849.77 & -28290.89726 & 127.0800885 \\
\hline 313 & 10849.77 & -28994.74054 & 127.2987557 \\
\hline 318 & 10849.77 & -29830.08772 & 127.9240809 \\
\hline 323 & 10849.77 & -30313.60747 & 127.4407971 \\
\hline
\end{tabular}


$\mathrm{Pb}^{+2}+$ druge $\rightarrow[\mathrm{Pb}-\text { druge }]_{\text {complex }}$

The law of the first-order rate for the reaction.

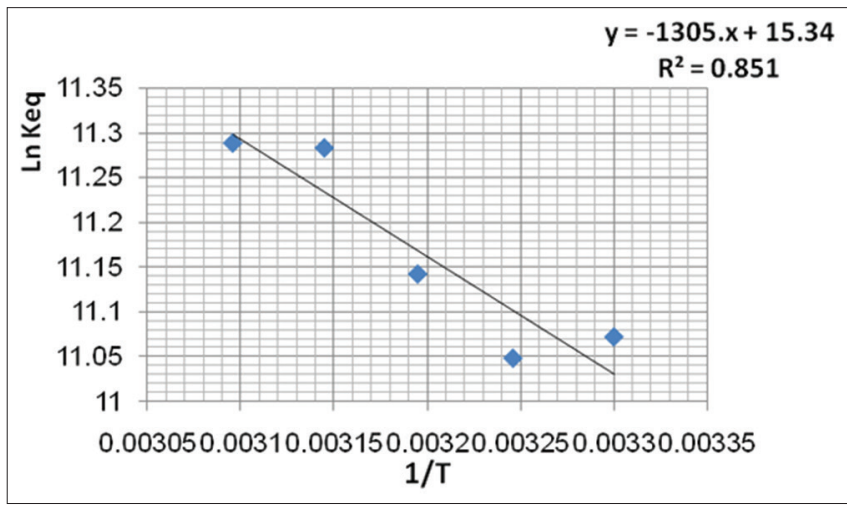

Fig. 6: Vant Hoff plot for the interaction of ( $\mathrm{Pb}[\Pi]-d r u g)$ complex at temperature $303,308,313,318$, and $323{ }^{\circ} \mathrm{K}$
$\mathrm{dA} / \mathrm{dt}=-\mathrm{k}[\mathrm{A}]$

$\ln \left[[\mathrm{A}] /\left[\mathrm{A}_{0}\right]=-\mathrm{kt}\right.$

$\ln \mathrm{A}-\ln \mathrm{A}_{0}=-\mathrm{kt}$

The law of seconed-order rate for the reaction.

$\mathrm{d}[\mathrm{A}] / \mathrm{dt}=-\mathrm{k}[\mathrm{A}]^{2}$

$1 /[\mathrm{A}]-1 /\left[\mathrm{A}_{0}\right]=\mathrm{kt}$

$A=$ Absorbance with different time of complex.

$\mathrm{A}_{0}=$ Absorbance in time zero of complex.

To evaluate the order of the interaction (drug- $\mathrm{Pb}$ ) complex from the plot of $1 / \mathrm{A}$ and $\ln \mathrm{A}$ against time $\mathrm{t}$, by application of Equation $(3,5)$.

\section{Reaction order and rate constant of (Pb-drug) complex}

To determine the order of the interaction of $\mathrm{Pb}$ ion with drug and from the through a plot of $(1 / \mathrm{A})$ aginst time $(\mathrm{t})$ are presented in Fig. 7 by the

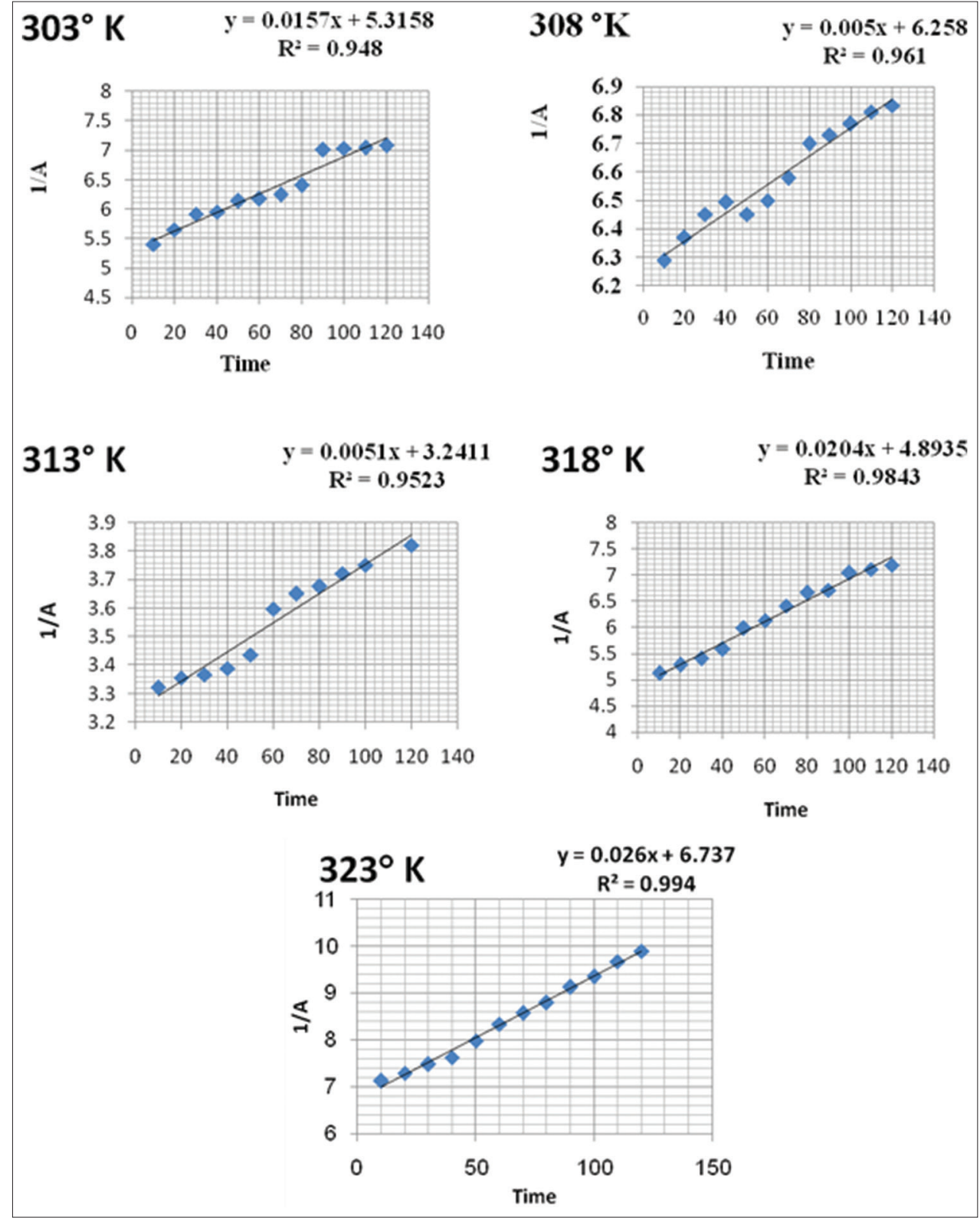

Fig. 7: The application of the second-order reaction for the complex of (drug-Pb) complex at temperature $303,308,313,318$, and $323{ }^{\circ} \mathrm{K}$ 
Table 6: Data for application the second-order equation for (2:1) (drug-Pb) complex at temperature $303,308,313,318$, and $323^{\circ} \mathrm{K}$

\begin{tabular}{|c|c|c|c|c|c|c|c|c|c|c|}
\hline \multirow[t]{2}{*}{ Time (min) } & \multicolumn{2}{|l|}{$303^{\circ} \mathrm{K}$} & \multicolumn{2}{|c|}{$308^{\circ} \mathrm{K}$} & \multicolumn{2}{|l|}{$313^{\circ} \mathrm{K}$} & \multicolumn{2}{|c|}{$318^{\circ} \mathrm{K}$} & \multicolumn{2}{|l|}{$323^{\circ} \mathrm{K}$} \\
\hline & $\mathbf{A}$ & $1 / \mathrm{A}$ & A & $1 / \mathrm{A}$ & A & 1/A & A & 1/A & A & 1/A \\
\hline 10 & 0.185 & 5.405 & 0.159 & 6.289 & 0.301 & 3.322 & 0.195 & 5.128 & 0.142 & 7.133 \\
\hline 20 & 0.177 & 5.650 & 0.157 & 6.369 & 0.298 & 3.356 & 0.189 & 5.291 & 0.137 & 7.299 \\
\hline 30 & 0.169 & 5.917 & 0.155 & 6.452 & 0.297 & 3.367 & 0.185 & 5.405 & 0.134 & 7.488 \\
\hline 40 & 0.168 & 5.952 & 0.154 & 6.494 & 0.295 & 3.389 & 0.179 & 5.587 & 0.131 & 7.634 \\
\hline 50 & 0.163 & 6.135 & 0.155 & 6.452 & 0.291 & 3.436 & 0.167 & 5.988 & 0.125 & 7.983 \\
\hline 60 & 0.162 & 6.173 & 0.154 & 6.499 & 0.278 & 3.597 & 0.163 & 6.135 & 0.119 & 8.346 \\
\hline 70 & 0.160 & 6.250 & 0.152 & 6.579 & 0.274 & 3.650 & 0.156 & 6.410 & 0.117 & 8.575 \\
\hline 80 & 0.156 & 6.410 & 0.149 & 6.699 & 0.272 & 3.676 & 0.150 & 6.666 & 0.114 & 8.792 \\
\hline 90 & 0.143 & 7.003 & 0.149 & 6.730 & 0.269 & 3.722 & 0.149 & 6.711 & 0.109 & 9.133 \\
\hline 100 & 0.142 & 7.032 & 0.148 & 6.770 & 0.267 & 3.752 & 0.142 & 7.042 & 0.107 & 9.357 \\
\hline 110 & 0.142 & 7.046 & 0.147 & 6.811 & 0.264 & 3.781 & 0.141 & 7.110 & 0.103 & 9.675 \\
\hline 120 & 0.141 & 7.082 & 0.146 & 6.834 & 0.263 & 3.799 & 0.139 & 7.211 & 0.101 & 9.899 \\
\hline
\end{tabular}

Table 7: The calculated first-order rat constant and second-order rate constant for (2:1) (drug-Pb) complex at temperature 303, 308, 313,318 , and $323^{\circ} \mathrm{K}$

\begin{tabular}{lll}
\hline $\begin{array}{l}\text { Temperature } \\
\left({ }^{\circ} \mathbf{K}\right)\end{array}$ & $\begin{array}{l}\text { (k) First-order rat } \\
\text { constant }\left(\mathbf{m i n} \mathbf{-}^{-1}\right)\end{array}$ & $\begin{array}{l}\text { (k) second-order rat constant } \\
\left(\mathbf{M}^{-1} \cdot \mathbf{m i n}^{-1}\right)\end{array}$ \\
\hline 303 & $2 \times 10^{-3}$ & $1.570 \times 10^{-2}$ \\
308 & $1 \times 10^{-4}$ & $5.00 \times 10^{-3}$ \\
313 & $1 \times 10^{-3}$ & $5.10 \times 10^{-3}$ \\
318 & $3 \times 10^{-3}$ & $2.04 \times 10^{-2}$ \\
323 & $3 \times 10^{-3}$ & $2.60 \times 10^{-2}$ \\
\hline
\end{tabular}

application of Equation (5), a straight line was obtained which indicates the second-order interaction between $\mathrm{Pb}$ ion and chelating agent with a rate constant illustrated in Table 6 which were calculated from the slope of the straight line.

The appliance of first- and second-order of the interaction is illustrated in Table 7, which illustrated the second-order rat constant for (drug-Pb) complex. The interaction between (drug- $\mathrm{Pb}$ ) complex follows the second order reaction kinetics, with a rate constant $\mathrm{k}=2.6 \times 10^{-2} \mathrm{M}^{-1} \cdot \mathrm{min}^{-1}$

\section{CONCLUSIONS}

The complex of the theophylline 1,3-dimethyl- xanthine (therapy drugs) with a hazard heavy metal lead (П), shows a high tendency of the complex formed, this was obvious from the value of the equilibrium constant that clarified a good complex. The thermodynamic parameters show that the complex is spontaneous with an electrostatic interaction and an increase in the order of orientation rate of complexation follows the second-order reaction kinetics which was confined by the straight line and a high rate constant.

\section{REFERENCES}

1. Lehninger AL. Mechanism of Transition in Magnetite at Low Temperatures. Phys Rev 1990;30:393.

2. Richards FM, Wyckoff HM, Allewel NM. Studies of stability constant on ternary chelates of bivalent. Neurosciences 1969; 18:901.

3. Thomas G. Medicinal Chemistry. London: John Wiley and Son Ltd.; 2003. p. 256.

4. Mukharjee GN, Ghosh TK. Hetero atom chemistry. Indian J Chem 1991;30A:1033-7.

5. Mukharjee GN, Ghosh TK. Thermodynamic-studies-of-transitionmetal-complexes-with-metforminhydrochloride-drug-in-20--vvethanolwater-mixture. J Indian Chem Soc 1991;68:194-6.

6. Vogel's Text book of Quantitative Chemical Analysis. $6^{\text {th }}$ ed. Singapore: Pears Edu Ltd.; 1989.

7. Belliardo F, Martelli A, Valle MG. HPLC determination of caffeine and theophylline in Paullinia cupana Kunth (Guarana) and Cola spp. Samples. Z Lebensm Unters Forsch 1985;180:398-401.

8. Persson CG. Development of safer xanthine drugs for treatment of obstructive airways disease. J Allergy Clin Immunol 1986;78:817-24.
9. Barnes PJ. Theophylline: New perspectives for an old drug. Am J Respir Crit Care Med 2003;167:813-8.

10. Schubert J. Interaction of metals with small molecules in relation to metal-protein complexes. In: Gurd FR, editor. Chemical Specificity in Biological Interactions. New York: Academic Press; 1954.

11. Jadhav SH, Sarkar SN, Patil RD, Tripathi HC. Effects of subchronic exposure via drinking water to a mixture of eight water-contaminating metals: A biochemical and histopathological study in male rats. Arch Environ Contam Toxicol 2007;53:667-77.

12. Patra RC, Swarup D. Effect of lead on erythrocytic antioxidant defence, lipid peroxide level and Thiol groups in calves. Res Vet Sci 2000;68:71-4.

13. Gurer H, Neal R, Yang P, Oztezcan S, Ercal N. Captopril as an antioxidant in lead-exposed Fischer 344 rats. Hum Exp Toxicol 1999; 18:27-32.

14. Ahearn GA, Mandal PK, Mandal A. Mechanisms of heavy-metal sequestration and detoxification in crustaceans: A review. J Comp Physiol B 2004;174:439-52.

15. Bard AJ, Flultener LR. Electrochemical methods fundamentals and applications. New York: John Wiley and Sons Inc.; 1980.

16. Peter P. Formation and stability of inorganic complex in solution. Anal Chem 1998;9:113-203.

17. Huned YJ. Study of the interaction between mono ammonium glycyrrhizin ate and bovine serum albumin. J Pharm Biomed Anal 2004;36:915-9.

18. Huned YJ. Studies on the interaction between 1-hexylcarbamoyl5-flurouracil and bovine serum albumin. J Mol Stricter 2005;738: 143-7.

19. Maccarthy K, Patrick D. Novel approach to Jop's methods. J Chem Educ 1986;63:162-7.

20. Bakhle YS. COX-2 and cancer: A new approach to an old problem. $\mathrm{Br}$ J Pharmacol 2001;134:1137-50.

21. Combaret L. Molecular mechanisms in exercise-induced cardio protection. J Physiol 2000;569:123-7.

22. Gibson RE, Loeffle OE. Absorption and luminescence of aromatic molecules. Am Chem Soc 2000;62:1324.

23. Stephen L. Chem1 Virtual. $2^{\text {nd }}$ ed. Canada: Burnaby Vancouver; 2004.

24. Ewing GW. Instrumental Methods of Chemical Analysis. New York: McGraw-Hill Inc.; 1990.

25. Kieffer F. In: Merian G, editor. Metals and Compounds in the Environment. Weinheim: VCH; 1991. p. 481.

26. Atikins PW. Physical Chemistry. $8^{\text {th }}$ ed. Oxford, Chicago: Oxford 
University Press; 2006.

27. Karlsson BC, Rosengren AM, Andersson PO, Nicholls IA. The spectrophysics of warfarin: Implications for protein binding. J Phys Chem B 2007;111:10520-8.

28. Morris S. Chemical Kinetics. New Delhi: IVY Publishing House, Sarup and Sons; 2003. p. 2-30.

29. Inczedy J. Analytical Applications of Complex Equilibrium. New York: John Wiley and Sons; 1996.
30. Onkari DD, Chawda MB, Thakur KS, Pawan K. Evaluation hypolipidemic activity of arogyavardhini and zpter tablet in cholesterolrich high fat diet (hfd) induced hyperlipidemia in Wistar rats. Int J Pharm Pharm Sci 2019;11:1-5.

31. Pisal P, Nigade G, Kale A, Pawar S. Development and validation of stability indicating rp-hplc method for simultaneous determination of aspirin, rosuvastatin, clopidogrel in bulk and pharmaceutical dosage form. Int J Pharm Pharm Sci 2018;10:51-6. 